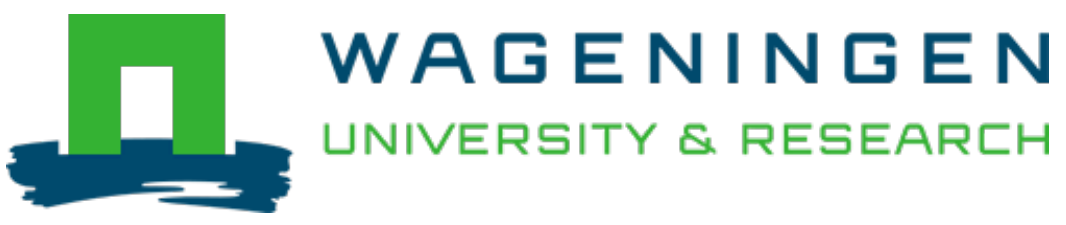

\title{
Defining urban open space governance and management
}

Urban Open Space Governance and Management

Jansson, Märit; Vogel, Nina; Fors, Hanna; Dempsey, Nicola; Buijs, A.E. et al

https://doi.org/10.4324/9780429056109-3

This article is made publicly available in the institutional repository of Wageningen University and Research, under the terms of article $25 \mathrm{fa}$ of the Dutch Copyright Act, also known as the Amendment Taverne. This has been done with explicit consent by the author.

Article $25 \mathrm{fa}$ states that the author of a short scientific work funded either wholly or partially by Dutch public funds is entitled to make that work publicly available for no consideration following a reasonable period of time after the work was first published, provided that clear reference is made to the source of the first publication of the work.

This publication is distributed under The Association of Universities in the Netherlands (VSNU) 'Article $25 \mathrm{fa}$ implementation' project. In this project research outputs of researchers employed by Dutch Universities that comply with the legal requirements of Article $25 \mathrm{fa}$ of the Dutch Copyright Act are distributed online and free of cost or other barriers in institutional repositories. Research outputs are distributed six months after their first online publication in the original published version and with proper attribution to the source of the original publication.

You are permitted to download and use the publication for personal purposes. All rights remain with the author(s) and / or copyright owner(s) of this work. Any use of the publication or parts of it other than authorised under article $25 \mathrm{fa}$ of the Dutch Copyright act is prohibited. Wageningen University \& Research and the author(s) of this publication shall not be held responsible or liable for any damages resulting from your (re)use of this publication.

For questions regarding the public availability of this article please contact openscience.library@,wur.nl 


\section{Defining urban open space governance and management}

\section{Märit Jansson, Nina Vogel, Hanna Fors, Nicola Dempsey, Arjen Buijs and Thomas B. Randrup}

\section{Introduction}

Urban open spaces (UOSs) have multiple values, with green spaces in particular providing numerous benefits for people and society through what are often referred to as ecosystem services (MEA, 2005). The amount of ecosystem services provided depends on the physical qualities and functions of UOS, and they lead to benefits which have values for people and society (HainesYoung \& Potschin, 2008) (see Chapter 8 for a definition of ecosystem services). The goal of UOS governance and management (G\&M) is often to develop spaces and especially their qualities with several aspects in mind, including, for example, biodiversity and the people using the spaces.

Professionals within the field of UOS G\&M work in a long-term perspective, on various scales and within various contexts, involving experience based on both practice and theory. Governance and management deal with the development and quality of most types of physical landscapes, often in urban settings (Pickett et al., 2001). Landscape professions are commonly divided into three tasks or even working phases: planning, design and management (CE, 2000; Rodiek, 2006; van den Brink et al., 2016) or possibly into two tasks: place-making (e.g. planning, design and construction) and place-keeping (e.g. management and maintenance) (Dempsey \& Burton, 2012). Landscapes are usually developed in a hierarchical, chronological way, beginning with a plan set by authorities on national, regional and local levels. Such plans influence the provision of UOS - for example, defining standards, rules and regulations. From there, more detailed designs on various scales are produced and then realised through construction, planting, etc. Management practices tend to 'end' this sequence or 'linear logic' of the landscaping working process. Such processes (planning, design, management) are becoming more interrelated with long-term management, which is increasingly being considered at the planning and design stages. Thus the logic is changing as landscape practices are developing. Further, there is an increasing challenge to democratic decision making in relation to consultation and participation by interest groups, users and other stakeholders. Therefore, new 


\section{BOX 2.1: DEFINITIONS}

Urban open space (UOS): Mainly unbuilt, often publicly accessible, area within a populated settlement, comprising vegetated 'green', water-dominated 'blue', derelict 'brown' and hard-surfaced 'grey' elements.

Green infrastructure (GI): The integrated, connective and cohesive network of UOS, as seen in a combined socioecological perspective.

UOS management: A strategic, inclusive and long-sighted approach of continued re-planning, re-design, re-construction and maintenance of UOS.

UOS maintenance: Operational processes and activities undertaken to maintain existing UOS.

UOS governance: Collaboration of government and non-government actors, with emphasis on power relations, decision making and resources (knowledge and funding) within a specific discourse and in accordance with relevant rules and regulations.

types of governance approaches, including co- and self-governance, are also affecting the traditional linear logic (Buijs et al., 2016). Such new approaches can evolve on various scales involving individuals, communities or entire institutions, comprising new sets of actors and practices.

\section{From UOS management to governance approaches}

UOS often comprises publicly accessible areas that are managed primarily within a local government domain (Randrup \& Persson, 2009; Dempsey \& Smith, 2014). Open space is commonly defined as being 'open urban public' (Shams \& Barker, 2019, p. 1), emphasising the access and use of people. However, approximately $50 \%$ of what is often considered to be UOS is privately owned (Fuller \& Gaston, 2009; Schmitt-Harsh et al., 2013), yet may still be accessible, physically or visually, and contribute much to the public in various ways through providing amenity and ecosystem services. Thus it is relevant to consider a scale from private to public when defining or dealing with UOS. During recent years, the prerequisites for UOS management have changed in several ways, leading to diversified governance approaches (see Box 2.1 for definitions of G\&M).

With the introduction of New Public Management (NPM) (Hood, 1995) (see Box 2.2), UOS management shifted from being a government issue for mainly the management organisations (e.g. local government organisations, housing companies, cemetery managers) to being a market issue, with contractors and private enterprises playing a new role as central actors. Thereafter, it has been moving 'from government to governance', with public administrations working collaboratively with a number of actors, including UOS users (Dempsey \& Smith, 2014).

The changes over time have increased the demands on UOS quality, with increased expectations for diverse and multiple functions. These expectations are also influenced by transformed societal needs connected to global megatrends: loss of biodiversity, lack of space, socioeconomic and environmental injustices as a result of climate change, urbanisation, globalisation, densification 


\section{BOX 2.2: NEW PUBLIC MANAGEMENT}

NPM is a reform movement initiated in the 1980s. It assumed from the outset that available resources were limited, and therefore, the focus was on increased efficiency. NPM was about re-inventing government and used a results-based orientation in combination with privatising and outsourcing as a means of achieving higher efficiency in public government. The public was seen as a provider of public goods for the users, who may be seen as costumers of a public good.

and migration (Newman et al., 2009; EEA, 2015). They induce shifts that affect UOS use, planning and management, in practice and in theory. Through the recent focus on anthropogenic concepts, such as ecosystem services (MEA, 2005) and nature-based solutions (NbS) (e.g. Maes \& Jacobs, 2015), it has been broadly acknowledged that UOSs are dynamic and require continued strategic management to meet new challenges.

Another main movement behind the shift within UOS management is the focus on public participation, which is widely supported in international conventions (e.g. UN, 1998; CE, 2000) as a way of enhancing democracy, accountability and transparency of management. Participation has long been argued as a means for social inclusion and other aspects of 'sustainable urban development'. In UOS routines, it can promote amenities and enhance social cohesion (Castell, 2010), integrate new knowledge, co-create values and offer more efficiency (Buijs et al., 2016). Participation is defined and systematised in different ways, according to the distribution of power and capacity for knowledge (Arnstein, 1969; Fung, 2006; Fors et al., 2015). However, particular responsibility still rests with local governments, as their routines, actions, encouragements and allowances are often paramount for adaptation of UOS management to the needs and requirements of local users (Carmona et al., 2008). Participation influences governments into new forms of governance, where stakeholders of various types can be represented in different types of 'governance arrangements' (Arnouts et al., 2012; Buijs et al., 2016).

These shifts, from government to governance, transformed societal needs and growing public participation, have led contemporary UOS management to an increased focus on co-development (Jansson et al., 2019). This has been illustrated in several recent studies addressing governance aspects within UOS management (e.g. Connolly et al., 2014; Molin \& Konijnendijk, 2014; Dempsey et al., 2016; Dennis \& James, 2016; MacKenzie et al., 2019). Combining G\&M in the development of UOS can be a way of safeguarding and acknowledging different values. As the practice of UOS management is being affected by new governance arrangements, beyond established structures and actors, challenges and discussions may come to involve the distribution of power, governmental legitimacy and sustainability discourse (Jansson et al., 2019).

\section{Definitions}

\section{Defining and conceptualising UOS management}

Within a landscape context, management is defined in slightly various ways. The 
European Landscape Convention (ELC) describes it as an 'action, from a perspective of sustainable development, to ensure the regular upkeep of a landscape, so as to guide and harmonize changes which are brought about by social, economic and environmental processes' (CE, 2000, p. 2). Thus the ELC focuses on upkeep but also on striving for sustainability (social, economic and environmental). This directs the attention to action, complexity and changes over time. However, 'regular upkeep' can be questioned, as it implies a focus on operations (maintenance) rather than on management in broad or strategic terms.

Jansson \& Lindgren (2012, p. 142) define 'landscape management' as 'activities performed by a management organisation in order to maintain and develop existing urban green space for users'. Likewise, Dempsey \& Smith (2014, p. 24) define 'place-keeping' as 'maintaining and enhancing [a place and] its quality to maximize the benefits for users'. Both definitions focus on users and the duality of maintaining and developing or enhancing UOS. According to Jansson et al. (2019), UOS management includes processes for implementing, maintaining and improving landscape structures, particularly physical landscapes, and people using and managing these'. This extends the focus to incorporate the fact that management also contributes to implementing or realising the design of spaces and that the management professionals and UOS users are core actors. Management of UOS is thus about more than 'maintaining' - it is also about providing UOSs which are of relevance and value from different perspectives and about adapting to actual needs and preferences over time.

Numerous studies argue the need not to limit management to maintenance and upkeep, referring to preservation of existing spaces and their qualities but to extend it to include planning and strategic approaches (Steiner, 1991; Morgan, 1991; Konijnendijk, 1999; Gustavsson et al., 2005; Randrup \& Persson, 2009; Jansson \& Lindgren, 2012). Therefore, particular attention has been given to the 'management organisation', which can be seen as differing from the 'management activities' performed (Gustavsson et al., 2005; de Magalhães \& Carmona, 2009). (See also Chapters 9 and 11, both of which emphasise the management organisation.) Furthermore, there are close links between the design of spaces and their management. Real challenges often arise when management is not factored in at the design stage. For example, Burton et al. (2014) discuss how competition designs of open spaces do not always involve managers in the consultation process. One could argue that a consequence of this is that many of the intended features get lost or lose their function some years after construction because they have not received the required ongoing maintenance as part of the management approach.

Management of UOS thus includes both ongoing maintenance and development or enhancement of user qualities in a longterm perspective (Jansson \& Lindgren, 2012; Dempsey \& Smith, 2014) and is intertwined with design (Burton et al., 2014). Pulling together all responsibilities for UOS under one organisation in this way, rather than the fragmented way in which design and management are often conducted, would help ensure that management is factored in at the design stage and that management is a way of achieving design goals.

\section{STRATEGIC MANAGEMENT Man-} agement and maintenance are terms that are often used interchangeably. Management can be used to describe the 'end stage' of the landscape development process (planning, design, construction, 
management), when in fact it refers to operational maintenance. Management is also strategic, and therefore sometimes called strategic management, and includes more than maintenance, with re-planning, re-design, re-construction and continued maintenance involved (Randrup \& Persson, 2009) (see Figure 2.1). Despite the common divisions between UOS management (or place-keeping) and planning and design (or place-making) within public authorities and academia, they are often intertwined in practice (Dempsey \& Burton, 2012; Jansson \& Lindgren, 2012). Strategic management has been supported by the development of governance approaches but also counteracted by changes, such as the market-based re-organisation through NPM (Hood, 1995). This has led to organisational changes within public park administrations, with a primary focus on operational management and a subsequent lack of strategic approaches (Randrup \& Persson, 2009). (Chapter 9 provides more details on the organisation of maintenance.)
According to de Magalhães \& Carmona (2009), the management of public spaces comprises four interlinked processes or tasks: (i) regulation of uses and conflicts between uses, (ii) maintenance routines, (iii) new investments and ongoing resourcing of public space and (iv) coordination of interventions in public space. The functions of UOS for people are then created and maintained in management that is either state centred, market centred or user centred. Gustavsson et al. (2005) and Randrup \& Persson (2009) divide management into three organisational levels or processes: policy (decision making), tactical (professional) and operational. The operational level concerns hands-on maintenance and upkeep; the tactical level creates overviews and plans; the policy level sets the overall directions and visions. (See Figure 11.1 in Chapter 11 for a more detailed description of the three levels of UOS management.)

Randrup \& Persson (2009) developed the 'park-organisation-user model', which comprises three dimensions (green spaces

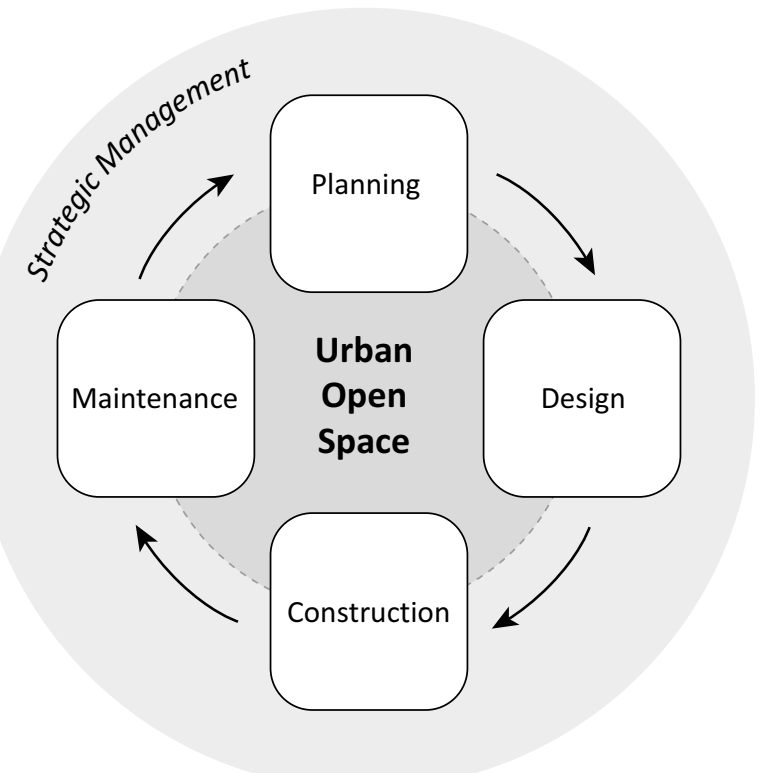

Figure 2.1 Strategic management of UOS. Source: Reproduced from Randrup \& Persson (2009) 
(or UOS), management organisations and users). The model acknowledges that all management activities concern a formal organisation (often an owner) and its relations to the UOS in question but include the users, also registered companies, charitable organisations, trusts and mutual and social enterprises. While much emphasis has been on socioecological relationships - for example, nature values for humans (Díaz et al., 2018) - the model insists that the means to establish these socioecological relationships should also be emphasised, thus illustrating and communicating UOS management (see Figure 2.2). The model has been applied to describe interconnections and interrelations between the three dimensions in relation to, for example, courtyards and playgrounds and in work related to landscape management theory (Jansson \& Lindgren, 2012).

\section{Defining and conceptualising UOS governance}

'Governance' has emerged during recent decades as a way of describing the steering of public resources in a wider perspective than in 'governing by government' (Jansson et al., 2019). Arts \& Visseren-Hamakers (2012, p. 4) define governance as 'the many ways in which public and private actors from the state, market and/or civil society govern public issues at multiple scales, autonomously or in mutual interaction'. Governing can be done by, with or without the state/authority. Governance in its strictest definition is in contrast to conventional government. It is characterised by a multi-centred steering system where public and private actors cooperate voluntarily in various relations rather than being enforced within a traditional hierarchy. Traditional top-down government, implying a division

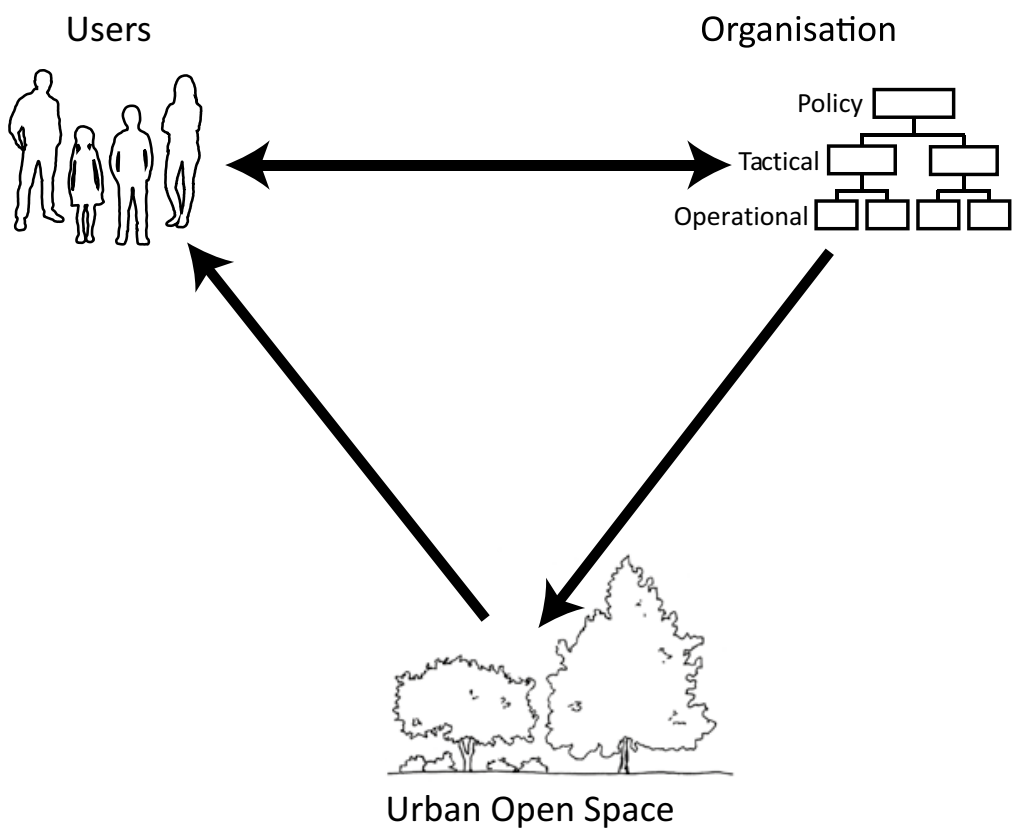

Figure 2.2 The park-organisation-user model with its three components: the organisations (managers), users and UOS. Source: Reproduced from Randrup \& Persson (2009) 
where politicians make decisions without active user involvement (Sehested, 2004), is thereby seen as outdated, illegitimate and ineffective. Instead, governance refers to new ways of steering and of organising steering processes in a postmodern society (Sehested, 2004; Arts \& Visseren-Hamakers, 2012), including policy networks, public participation and public-private partnerships (Arts \& Visseren-Hamakers, 2012). An important underpinning concept is that no single actor holds all the answers to a collective problem and that the actors are, therefore, dependent on collaboration (Sehested, 2004).

Within the context of UOS, governance has been defined as 'the sphere of relations between [local] government and other actors in civil society or non-governmental sectors - including the private sector and community' (Smith et al., 2014, p. 53). Governance approaches may not always lead to visible changes in the actual UOS, but their processes are different from 'traditional' actions by government, as there are various actors involved in development, implementation and communication. Thus it may have a different legitimate bearing.

Governance in relation to UOS development can be understood by applying the concepts of 'policy arrangements' and even governance arrangements (Arnouts et al., 2012; Jansson et al., 2019). The outcomes of such arrangements are determined by the resources included, the network of actors, and their roles and relations (Arnouts et al., 2012). These arrangements take place in public domains (policy domains), where formal regulations, public interests and societal values must be considered. Decision making and implementation are operationalised through coordination and collaboration but with certain rules, legitimacy and power distribution as set through policy instruments. With the changing role and influence of the state and/or authorities, governance arrangements range from hierarchical to closed co-governance, open co-governance and self-governance, as well as from local to global (Arts \& VisserenHamakers, 2012).

The 'policy arrangement model' (Arts et al., 2006) illustrates the core components of a governance arrangement in a policy domain and their interrelations (see Figure 2.3). The 'discourse' is the content and direction of the policy domain, 'rules of the game' include formal and informal laws, rules and regulations, 'resources' may come in many forms (e.g. spaces, competences, time, money, power) and 'actors' include public organisations, businesses, users and non-government organisations (NGOs) (Arts et al., 2006).

Molin (2014) introduced the concept of 'place-based governance' in the context of UOS, acknowledging the local connections between different actors and in relation to specific sites. The long-term development of a site may depend on whether governance arrangements can offer a well-functioning context and direction for the organisation. Through continuous involvement, actors, skills and knowledge can be developed and transferred, and building such capacities can lead to success in the long-term management of UOS.

\section{Co-governance of UOS management: a combined approach}

There are many similarities and overlaps between G\&M of UOS, as both concepts place the focus on the public domain and its quality and development. The main aspects of UOS G\&M can be brought together in a combined G\&M model and theoretical framework (Jansson et al., 2019). The G\&M model can be used to explore governance aspects of UOS management, including organisation form and development 


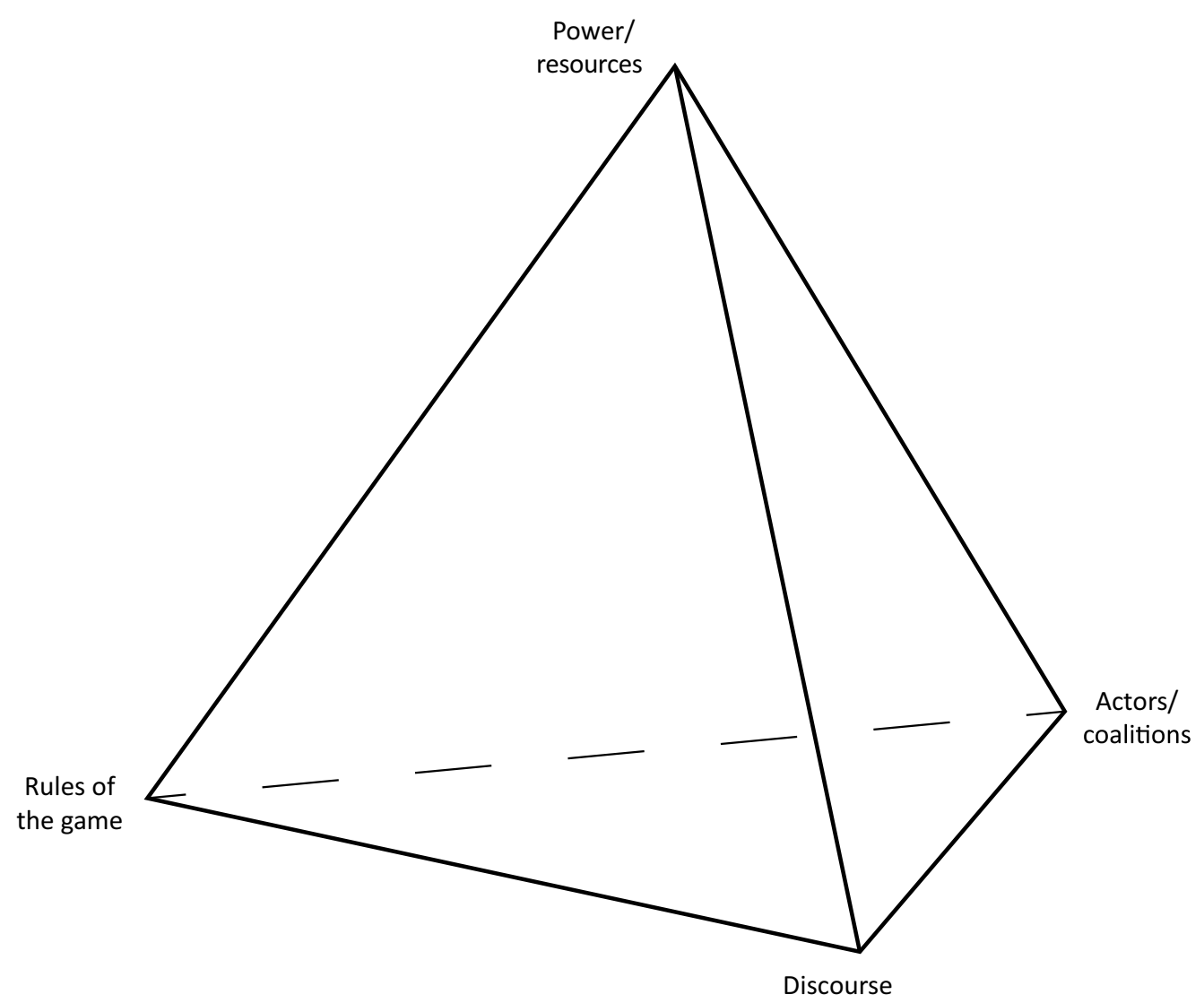

Figure 2.3 The tetrahedron of policy arrangements. Source: Reproduced from Arts et al. (2006)

of spaces (Figure 2.4). The G\&M model is based on the core of UOS G\&M in the park-organisation-user model (see Figure 2.2), the policy arrangement approach (see Figure 2.3) and the hierarchical closed and open co- and self-governance scale defined by Arts \& Visseren-Hamakers (2012). It contains the three interrelated dimensions of the park-organisation-user model: 'UOS', 'public actors' and 'users/private enterprises'. The UOS in question can be private, public or somewhere in between and thus not necessarily publicly accessible. The four dimensions of the policy arrangement tetrahedron are shown via the 'rules of the game', and these are listed next to each 'actor' as arrows for user and administration 'discourses' between any relevant actors. 'Resources' are listed next to the related 'power' arrows, indicating the level of power through the thickness of the arrows (Figure 2.4). Various governance modes (Arnouts et al., 2012) can be illustrated by elaborating the arrows in the model.

SELF-GOVERNANCE Self-governance implies that management is organised and conducted by the users, with no or little involvement from the 'government' - for example, local governments or other authorities. Ideally, this implies that non-government actors steer their own affairs with a high degree of autonomy. Some boundaries or rules are often set, and the government organisation can facilitate and stimulate operations, but non-government actors are mainly responsible in this arrangement (Arnouts et al., 2012). These actors can for 


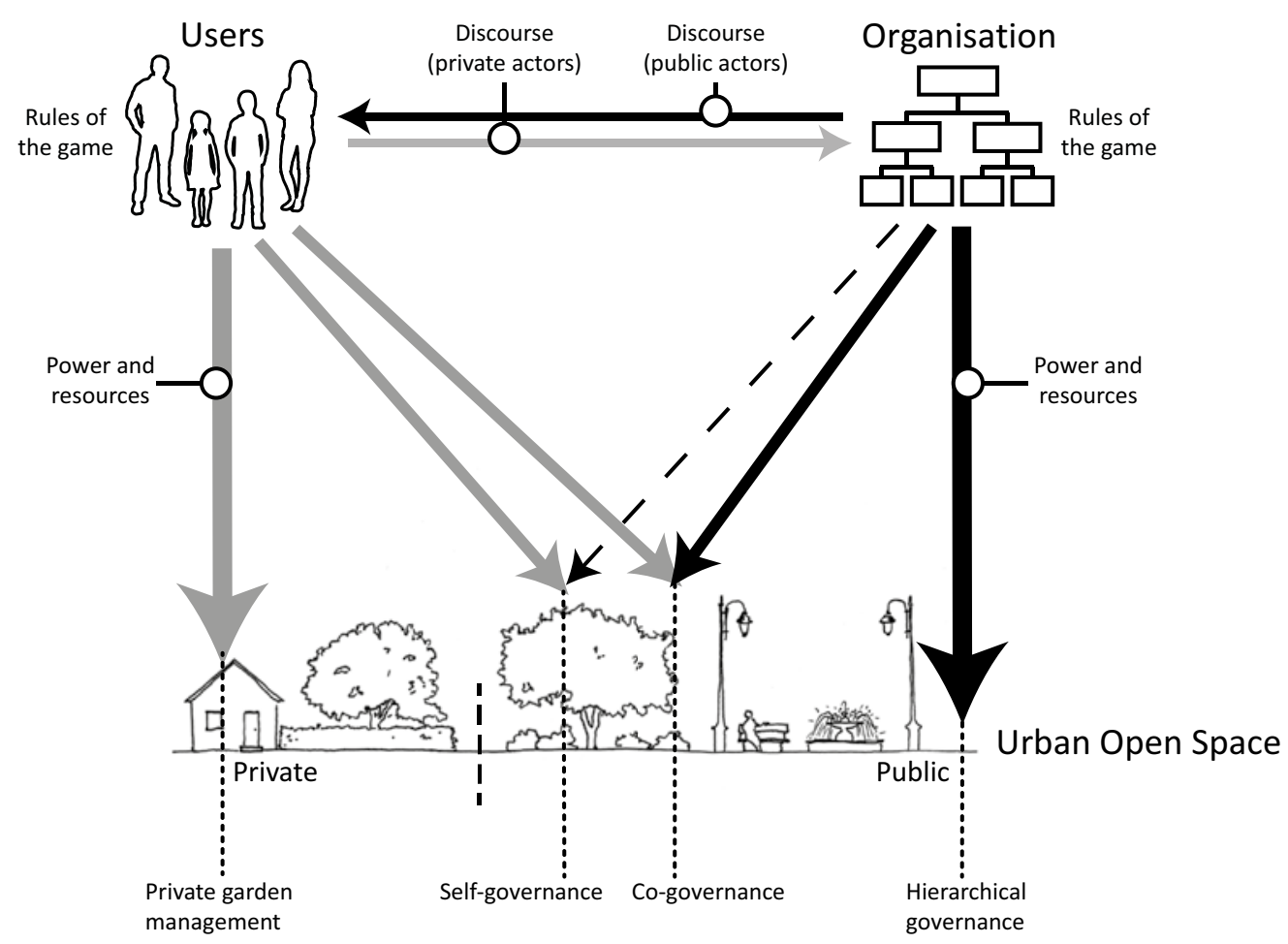

Figure 2.4 The combined G\&M model. Source: Reproduced from Jansson et al. (2019)

example be individuals, local groups or even social enterprises, like in Manor Fields Park in Sheffield, UK (Box 2.4 and Figure 2.6).

Initiatives leading to self-governance tend to be taken by users, NGOs or other non-government actors aiming to take over the management and steering of resources from conventional governmental organisations for example, to safeguard spaces or their quality. However, there are also examples of local governments encouraging or initiating projects leading to self-governance for financial or social sustainability reasons.

One form of self-governance is urban commons. In the diversified context of contemporary urbanisation, commoning is considered a self-organised governance practice that can contribute coping capacity for various challenges, such as austerity measures, endangered resources, inequalities and uncertain development conditions (Bollier \& Helfrich, 2012; Vogel, 2017). The practice of commoning comprises the collective management of a resource by its users (its 'commoners'). In its most radical form, it can comprise protest and occupy movements, where local residents reclaim endangered urban resources (Borch \& Kornberger, 2015). More moderate forms include do-it-yourself urbanism and 'sustainable stewardship', which can foster inclusiveness and community capacities and strengthen identification and belonging (Bradley, 2015). These additional values show that commons have potential mainly for social relations to a 'resource' (Euler, 2016). Claiming UOS as commons thus offers different value capacities, user relations and management practices compared with conventional UOS management. Despite the self-organised nature of commoning, there are examples of commons being established by local governments, such as the \#Pixlapiren project in Helsingborg, Sweden (see Box 2.3 and Figure 2.5). 


\section{BOX 2.3: CHANGING FROM OPEN CO-GOVERNANCE TO SELF- GOVERNANCE - THREE CASES}

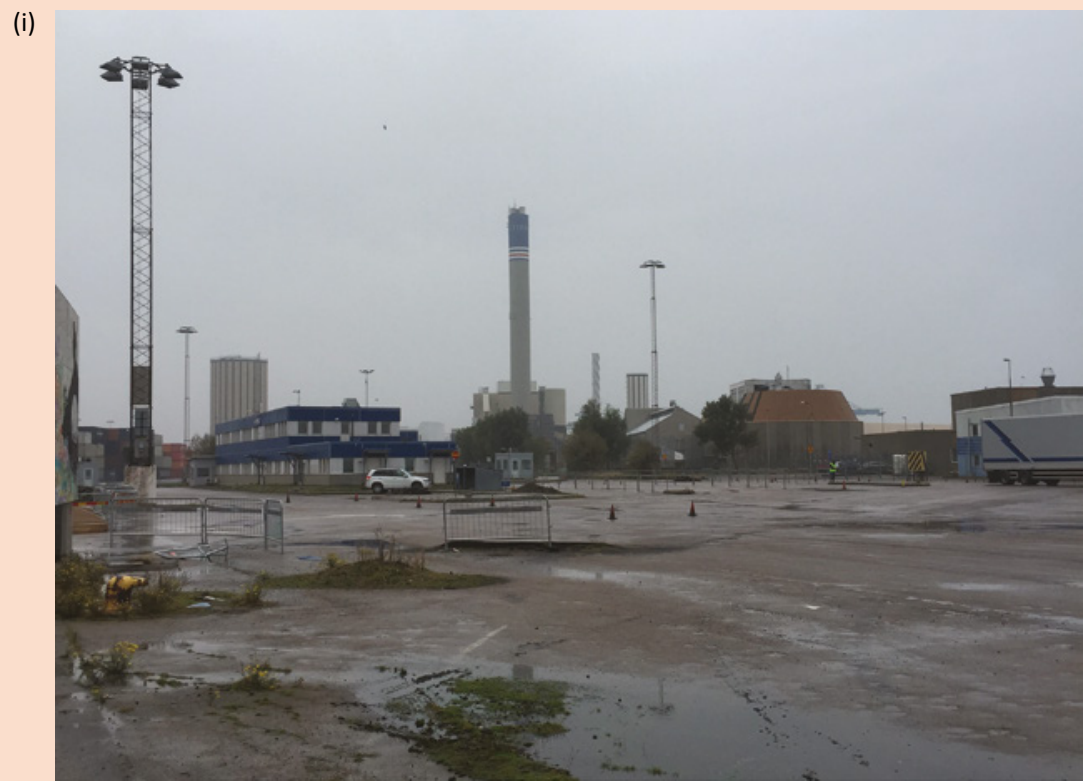

(ii)

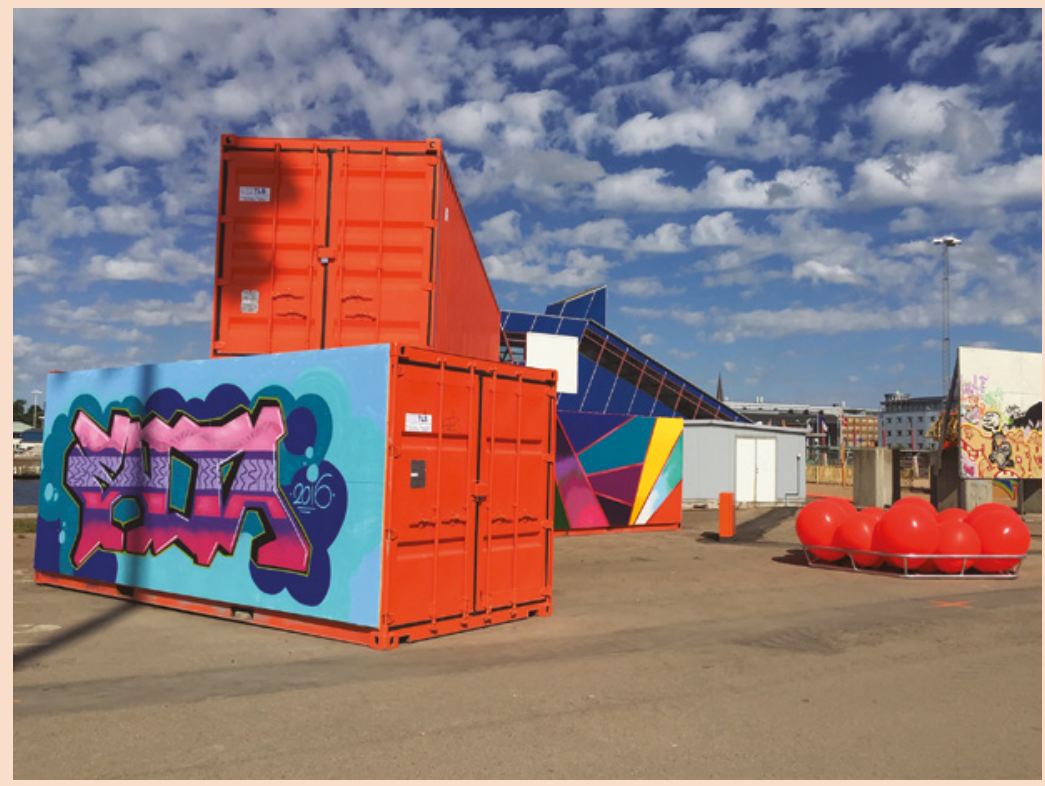

Figure 2.5 (i) The site at the beginning of the \#Pixlapiren project and some of its new uses developed by groups of 'pixelators', (ii) location for a street art festival 
(iii)

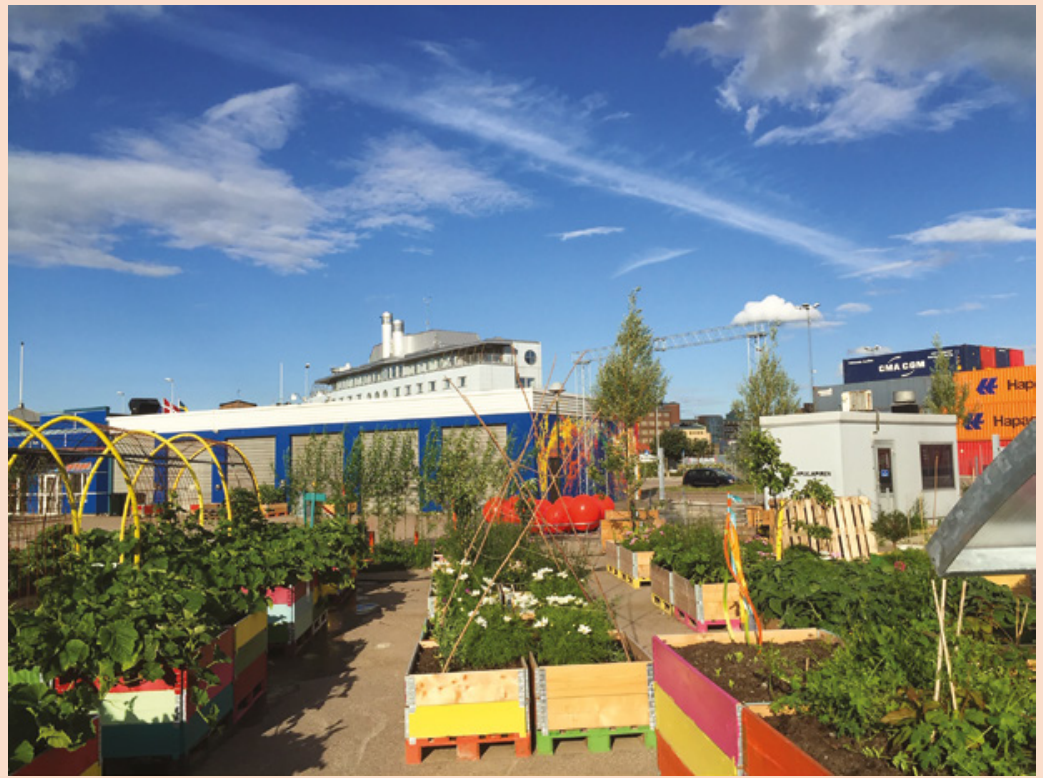

(iv)

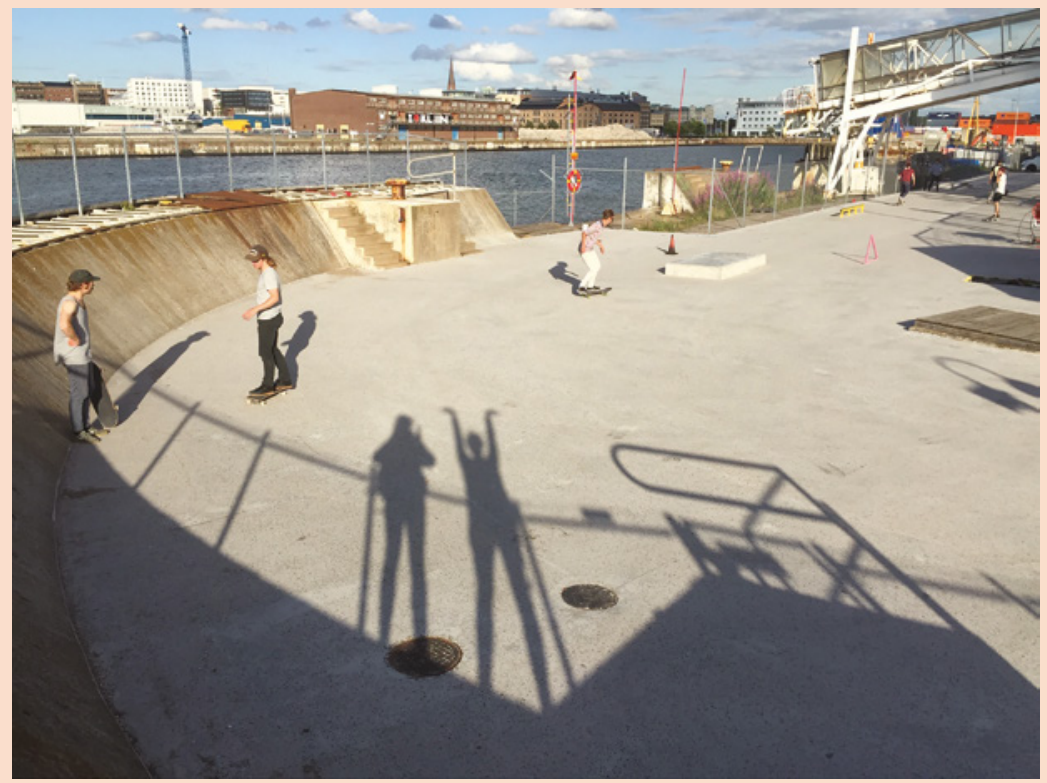

Figure 2.5 (iii) community gardening plots and (iv) a skateboard park using the existing slope of the pier with a new surface. Photos: Nina Vogel

\#Pixlapiren in Helsingborg, Sweden, is a local government initiative exploring new forms of co-development on a 4-hectare pier in conjunction with a large urban renewal project. It is envisioned as a 'test bed' where interested stakeholders can meet, initiate ideas and form place identities in order to strengthen local democracy 
and challenge segregation problems. Development spaces ('pixels') measuring $10 \mathrm{~m} \times 10 \mathrm{~m}$ are granted to all interested stakeholders (local residents, organisations, groups) within the eight- to ten-year project. The rules of the game are set through a contract as the basis for agreement between the actors ('pixelators') and the local government. \#Pixlapiren includes the challenge to create interest and ownership among users as the local government remains in (restrained) power over 'urban common' and connected resources. Possibilities include testing democratic practices and new tools to handle changing multiple uses on-site, including urban gardening, street art, skateboarding, beach volley, waterskiing, festivals and workshops. The intention is that the pixelators will form, use and manage the space collectively in true self-governance.

Boscoincittà (the Forest in the City) is a public nature park in a peri-urban green belt in Milan, Italy. In 1974, the Milan local government granted a concession to the NGO Italia Nostra for redevelopment of 35 hectares of abandoned farmland. This area was then developed into a park as a co-governance process involving residents, NGOs and authorities. An important discourse within Boscoincittà was to counter the effects of urbanisation, increase green space connectivity and provide recreational opportunities. Financial resources were mobilised from the public, NGOs and local government so that the park could increase its scale to over 120 hectares, including woodlands, meadows, wetlands and allotment gardens, strongly contributing to green space accessibility. The number and diversity of active users involved as actors and the dominant modes of governance have changed over time. Groups of users have locally designed and managed parts of the park since 1974, and the rules of the game have changed from co-governance to self-governance. The NGO Italia Nostra is responsible for Boscoincittà's overall development and management, but several park sections are managed by groups, including students, scouts and community associations. Cooperation with administrations has been challenging for Italia Nostra, but local government has also played an important supporting role, providing resources such as land, allowances and a formal lease contract.

The nature association De Ruige Hof (the Wild Court) was established in 1986 by a group of members of the public seeking to protect spontaneously emerging nature on abandoned construction sites in south-east Amsterdam, the Netherlands. After meeting with the City of Amsterdam local government, De Ruige Hof took over the management of the De Riethoek site and a few years later also a second area, Klarenbeek. It now manages 13 hectares of nature and has about 450 members, 50 active volunteers and a budget of around $€ 20,000$ annually arising from membership contributions, donations and government support. De Ruige Hof has a management committee and employs a part-time coordinator. The aim is to bring nature and users closer together by organising a variety of activities, mostly in relation to management. This contributes to conservation and development of green space with increased biodiversity. 


\section{BOX 2.4: SELF-GOVERNANCE IN MANOR FIELDS PARK, SHEFFIELD, UK}

Green Estate Ltd is a social enterprise with a commercial arm that began life as an environmental regeneration project in 1998 in the Manor Castle area in Sheffield, United Kingdom. It manages approximately 300 hectares of green space in the area, ranging from recreation grounds, parks and amenity green spaces to demolition/development sites (Figure 2.6). The social arm focuses on the management of existing UOS and engages in 'place-making' of new areas. To reduce the reliance on grant funding, Green Estate has a number of commercial activities to generate income, including UOS management, grounds maintenance, green waste recycling and composting and green roof installation. The social and the commercial arms have their own budgets, contracts and staff, including qualified and skilled landscape architects, managers and arboriculturalists.

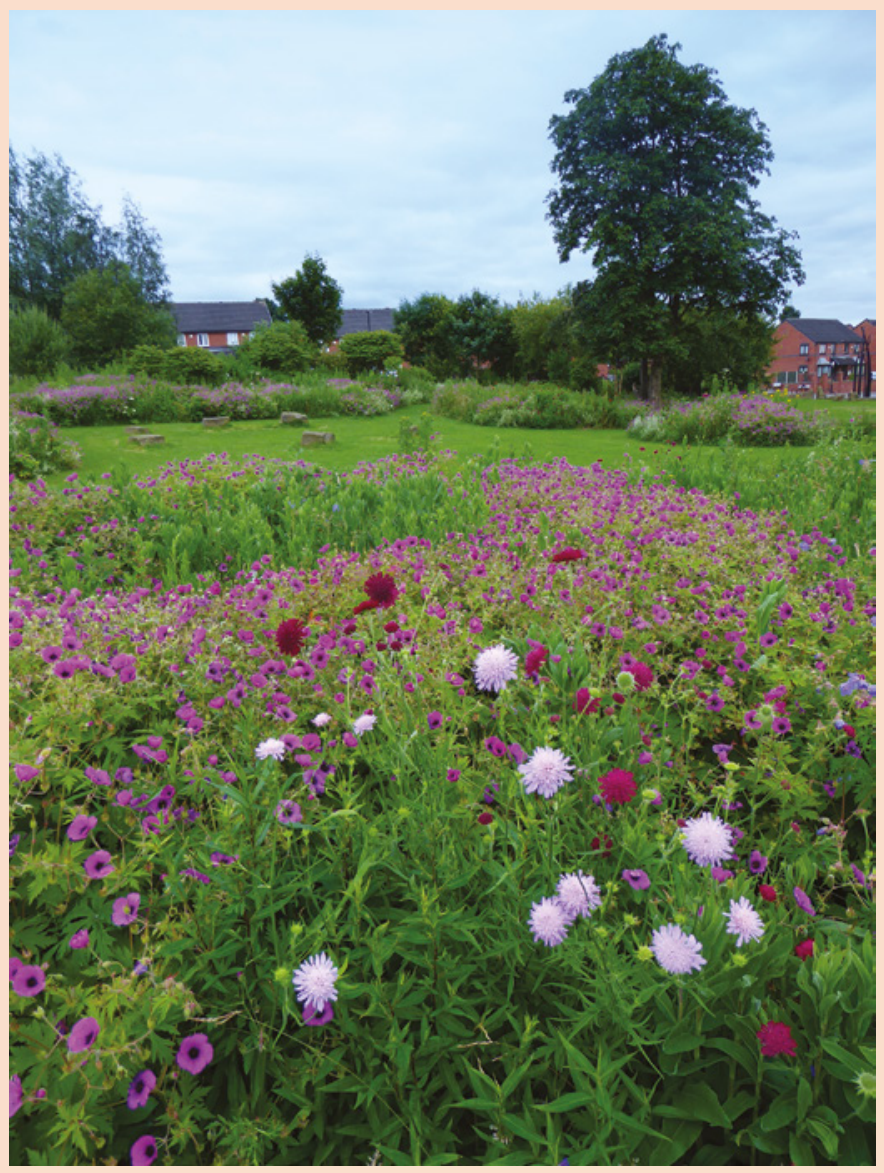

Figure 2.6 Perennial meadow planted and maintained by Green Estate in Manor Fields Park, Sheffield. Photo: Peter Neal 
Staff training and employment involve team members working on-site in a role similar to that of a traditional park warden but with extensive horticultural training. There is much contact with the public on matters of anti-social behaviour and inter-agency networking (e.g. police, fire service, health professionals), alongside the management and maintenance tasks. This skills base generates high-quality volunteers and 'place-keeping' work placement opportunities. Initially, Green Estate faced a lack of constructive community involvement. Therefore, there has been ongoing consultation before, during and after the completion of all Green Estate projects in the area since 1999. Funding comes from a mixture of public projects and commercial projects, allowing Green Estate to move from $100 \%$ grant funded in 2004 to $100 \%$ self-sustaining 15 years later.

CO-GOVERNANCE In co-governance, both government and non-government actors collaborate, forming either a tight-knit or more loosely organised group (Arnouts et al., 2012). This means that the authority for example, a local government - transfers some of its power to a certain group or groups of users. Co-management of UOS in public and semi-public areas has received increasing attention during recent decades. In some cases, people have initiated co-management by engaging in the management of nearby UOS. In other cases, this has been initiated top-down - for example, by local government organisations. Co-management areas can also be created in a collaborative way, with users participating and managers facilitating actions to get the co-management established. Depending on the organisation and involvement in these collaborations, co-management can sometimes be defined as either closed (tight-knit) or open (loose-knit).

Open co-governance is the more looseknit form of co-governance, which often has fewer different types of actors involved and less steering than closed governance. Examples of open co-governance are community gardens and co-management of green spaces (e.g. parks), where authorities collaborate with actors engaged in the maintenance practices, often people who live nearby.
A small-scale example of open co-governance is co-management zones, a concept that bears some similarities to urban commons as it involves publicly owned UOS where local ownership is built through active involvement by local residents (Colding et al., 2013). Co-management of UOS, such as community gardens, generally involves the entire green space, affecting its overall characteristics under users' own rules. Co-management zones instead give local residents the possibility to use, develop and manage some defined spaces, while public managers continue to control the main area and its characteristics and quality (Fors et al., 2018). Thus, residents can influence the area through long-term co-management activities, but the physical space where participation takes place is restricted. Involvement in co-management zones may be individual and, therefore, mainly independent of the collective organisation, which constitutes a distinct difference from urban commons. In closed co-governance arrangements, the collaboration is more tight-knit and often much more dependent on an organisation, such as a local government, taking overall responsibility. An example of closed co-governance is Burgess Park in London, UK (Box 2.5 and Figure 2.7). 


\section{BOX 2.5: CLOSED CO-GOVERNANCE IN BURGESS PARK, LONDON, UK}

Burgess Park is the largest park in the London borough of Southwark. Surrounded by one-fifth of the most deprived wards in London, it is central to ambitious highdensity urban regeneration. The park occupies 51 hectares and was built over three decades from the mid-1950s as a number of UOSs were brought together. Greater London Corporation gave the park and responsibility for it to Southwark Council in the mid-1980s. Numerous projects were then undertaken before Burgess Park re-opened in 2012.

A grounds maintenance contract contributes to sustaining the capital investments made, with the focus on safety, cleanliness and access. The maintenance work is contracted out by the local government to a private contractor, including a post to coordinate opportunities for structured volunteering sessions. The private contractor also employs five locally recruited apprentices annually to study horticulture, provides capital investment for new machinery and equipment and works with ecology and conservation organisations and local 'friends groups'. The local government provides capital investment for new vehicles and major plant items. The head gardeners in Southwark (employed by the contractor) are local ecology and conservation champions. Other actors involved include the local rugby club, a community theatre group, an organic allotment group and nature groups.

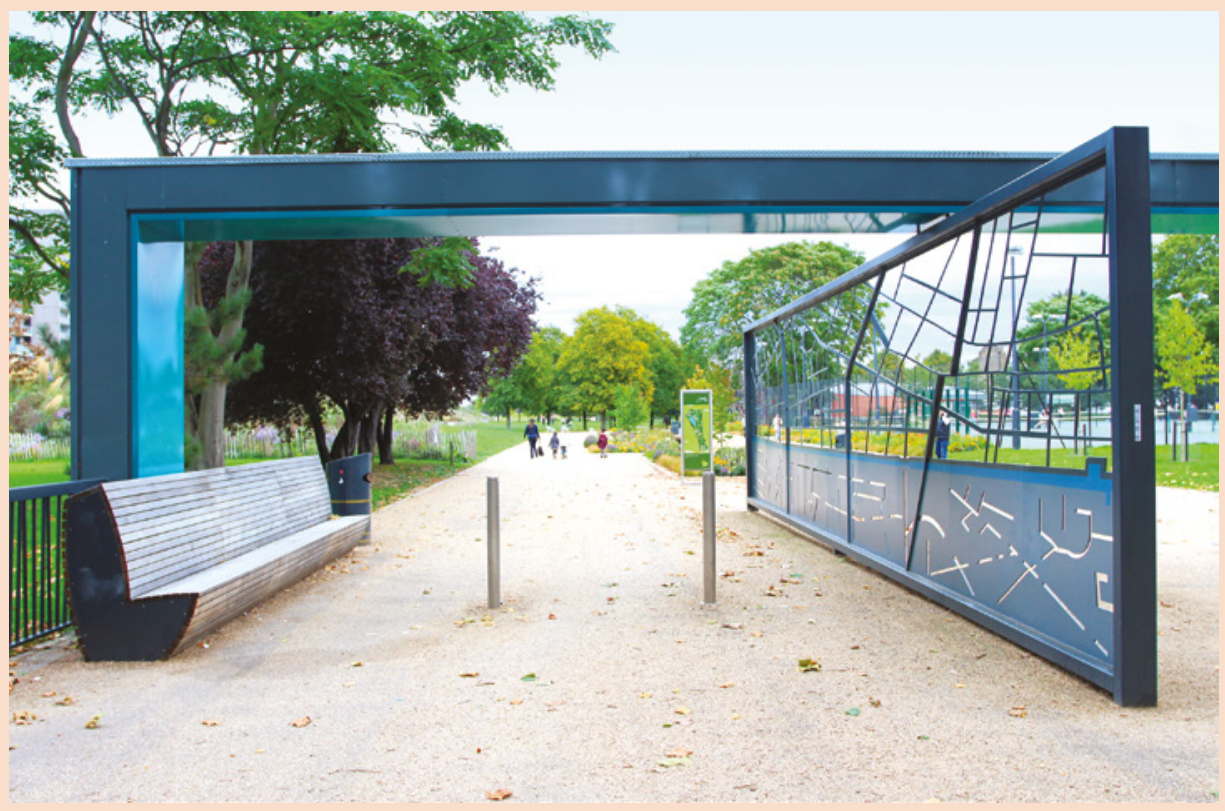

Figure 2.7 The western entrance of Burgess Park, London. Photo: Peter Neal 
Depending on the local government structure, schoolyards can be included in the realm of the local (public) management protocol or, as seen in, for example, the UK, schools can manage their own grounds without local government control and management. In Sweden, schoolyard greening is sometimes conducted in a temporal closed co-governance approach (Jansson \& Mårtensson, 2012). Contemporary schoolyards are often dominated by paved surfaces and mostly managed in quite conventional ways by local government managers and maintenance staff or contractors. However, green and varied schoolyards are promoted for learning and varied play, where the approach to schoolyard management and use has been emphasised as being of major importance (Malone \& Tranter, 2003). This has led to an international trend of 'schoolyard greening', where activities can include 'gardening, naturalisation, habitat restoration, tree planting and other collaborative efforts to bring nature back to the school ground' (Bell \& Dyment, 2008, p. 78).

Schoolyard greening can be achieved in a collaboration between various actors, including teachers and other school staff, local government planners, managers and maintenance staff, private contractors, local organisations or NGOs, parents and community, as well as with participating pupils (Jansson \& Mårtensson, 2012). This is a shift in actors and power relations, creating a governance arrangement that is different from conventional schoolyard management 'by government'. These projects can often be considered closed co-governance arrangements, with the authority keeping much control in a short-term stabilisation process during the project period.

\section{Combined understanding for strategic and inclusive development}

Combined G\&M of UOS has become increasingly evident and necessary, as highlighted by Dempsey \& Burton (2012), Molin (2014) and Jansson et al. (2019). The practice of UOS management can be visualised in combination with a conceptual governance arrangement, where both G\&M relate to physical UOS settings. Addressing G\&M in combination opens up possibilities for an UOS development that is both strategic and inclusive, with increased understanding of participatory approaches, overcoming of barriers and increased organisational learning. By highlighting the interrelations between governance and management, the theoretical underpinnings and understanding of G\&M processes can be strengthened, and new forms of practices in relation to UOS and their development can be encouraged.

The focus on actors and their approaches and interrelations is paramount in G\&M of UOS. Users, and creation of benefits for users, must dominate the understanding of what these practices are all about (Randrup \& Persson, 2009; Dempsey \& Smith, 2014). Managers must also be at the core, with organisations and roles that are changing and developing along with the shift in management and the introduction of new and varying governance approaches (Fors et al., 2018). Although the shift is already a reality in many aspects, such structural changes might take time. Furthermore, the effects of these shifts are still rather poorly studied, concerning new management roles and their implications, including effects on the actual UOS relevance and quality (Fors et al., 2015). 
Governance within UOS management faces challenges as the consequences of megatrends, participatory approaches and local government steering approaches. As an example, austerity has caused major challenges to local government UOS budgets in the UK (Neal, 2016). There is also variation in what drives user involvement or what might underpin a lack of involvement. Some communities in richer parts of a city may have strong social capital in terms of well-educated and well-connected people. They are likely to have a stronger capacity to deal with, for example, the rules of the game or to access financial resources than less well-connected groups in more economically deprived areas. Funding sources may dictate the governance arrangements when stipulating the conditions. In the UK, in some cases (e.g. the UK's National Heritage Lottery Fund), funding will only be awarded when effective and sustained community involvement is demonstrated. Where new governance structures and agreements are increasingly required, for example, in the UK, dwindling public-sector funding is causing some local governments to apply NGO-led management of public spaces simply in order to maintain their UOS. Thus local communities and the third sector are playing an increasingly influential role in governance, but so do also private investors (developers), leading to the partial privatisation of UOS. It is currently unclear how issues concerning the transparency of arrangements and responsibilities can be resolved (Dempsey et al., 2016).

These developments and their local and national variations call for a more coherent understanding of processes in an approach where existing theories can be brought together, as in the combined G\&M model (Figure 2.4). Governance of UOS management now requires a greater dynamic in the approach to the co-development of UOSs and their qualities, compared with conventional approaches. This dynamic can include new ways of implementing design, knowledge and improvements through input and collaboration by different actors and through the possibility for constant development of UOS. This affects how UOS management can contribute to sustainable development. As governance thinking is increasingly becoming mainstream in practice, new knowledge, including well-functioning tools for its implementation and analysis, will be required.

\section{References}

Arnouts, R., van der Zouwen, M. \& Arts, B., (2012). Analysing governance modes and shifts - Governance arrangements in Dutch nature policy. Forest Policy and Economics. 16(C), 43-50.

Arnstein, S.R., (1969). A ladder of citizen participation. Journal of American Institute of Planners. 35(4), 216-224.

Arts, B., Leroy, P. \& van Tatenhove, J., (2006). Political modernisation and policy arrangements: A framework for understanding environmental policy change. Public Organization Review. 6(2), 93-106.

Arts, B. \& Visseren-Hamakers, I.J., (2012). Forest governance: Mainstream and critical views. ETFRN News. 53, 3-10.

Bell, A.C. \& Dyment, J.E., (2008). Grounds for health: The intersection of green school grounds and health-promoting schools. Environmental Education Research. 14(1), 77-90.

Bollier, D. \& Helfrich, S., (2012). Wealth of the Commons. A World Beyond Market and State. Amherst, MA: Levellers Press.

Borch, C. \& Kornberger, M., (2015). Urban Commons: Rethinking the City. London: Routledge.

Bradley, K., (2015). Open-source urbanism: Creating, multiplying and managing urban commons. Footprint. 9(16), 91-108.

Buijs, A., Elands, B., Havik, G., Ambrose-Oji, B., Cvejic, R., Debellis, Y., . . Železnikar, Š., (2016). Innovative Governance of Urban Green Spaces: Learning from 18 Innovative Examples 
Across Europe. Brussel: European Union's 7th Framework Program.

Burton, M., Dempsey, N. \& Mathers, A., (2014). Connecting making and keeping: Design and management in place-keeping. In: N. Dempsey, H. Smith \& M. Burton (eds.) Place-Keeping: Open Space Management in Practice. London: Routledge. 125-150.

Carmona, M., de Magalhães, C. \& Hammond, L., (2008). Public Space: The Management Dimension. London: Routledge.

Castell, P., (2010). Involving tenants in open space management: Experiences from Swedish rental housing areas. Urban Geography. 31(2), 236-258.

Colding, J., Barthel, S., Bendt, P., Snep, R., van der Knaap, W. \& Ernstson, H., (2013). Urban green commons: Insights on urban common property systems. Global Environmental Change. 23, 1039-1051.

Connolly, J.J.T., Svendsen, E.S., Fischer, D.R. \& Campbell, L.K., (2014). Networked governance and the management of ecosystem services: The case of urban environmental stewardship in New York City. Ecosystem Services. 10(December), 187-194.

CE, (2000). European Landscape Convention. Council of Europe.

de Magalhães, C. \& Carmona, M., (2009). Dimensions and models of contemporary public space management in England. Journal of Environmental Planning and Management. 52(1), 111-129.

Dempsey, N. \& Burton, M., (2012). Defining place-keeping: The long-term management of public spaces. Urban Forestry \& Urban Greening. 11(1), 11-20.

Dempsey, N. \& Smith, H., (2014). Understanding place-keeping of open space. In: N. Dempsey, H. Smith \& M. Burton (eds.) Place-Keeping: Open Space Management in Practice. London: Routledge. 13-29.

Dempsey, N., Burton, M. \& Duncan, R., (2016). Evaluating the effectiveness of a cross-sector partnership for green space management: The case of Southey Owlerton, Sheffield, UK. Urban Forestry \& Urban Greening. 15, 155-164.

Dennis, M. \& James, P., (2016). User participation in urban green commons: Exploring the links between access, voluntarism, biodiversity and well being. Urban Forestry \& Urban Greening. 15, 22-31.
Díaz, S., Pascual, U., Stenseke, M., Martín-López, B., Watson, R.T., . . . et al., (2018). Assessing nature's contributions to people. Science. 359(6373), 270-272.

EEA, (2015). European Environment - State and Outlook 2015: Assessment of Global Megatrends. Copenhagen: European Environment Agency.

Euler, J., (2016). Commons-creating society: On the radical German commons discourse. Review of Radical Political Economics. 48(1), 93-110.

Fors, H., Molin, J.F., Murphy, M.A. \& Konijnendijk van den Bosch, C., (2015). User participation in urban green spaces - For the people or the parks? Urban Forestry \& Urban Greening. 3, 722-734.

Fors, H., Nielsen, A.B., Konijnendijk van den Bosch, C. \& Jansson, M., (2018). From borders to ecotones - Private-public co-management zones in urban woodland edges bordering private housing. Urban Forestry \& Urban Greening. 30, 46-55.

Fuller, R.A. \& Gaston, K.J., (2009). The scaling of green space coverage in European cities. Biology Letters. 5(3), 352-355.

Fung, A., (2006). Varieties of participation in complex governance. Public Administration Review. 66(1), 66-75.

Gustavsson, R., Hermy, M., Konijnendijk, C. \& Steidle-Schwahn, A., (2005). Management of urban woodland and parks - Searching for creative and sustainable concepts. In: C.C. Konijnendijk, K. Nilsson, T.B. Randrup \& J. Schipperjin (eds.) Urban Forests and Trees. Heidelberg: Springer. 369-397.

Haines-Young, R. \& Potschin, M., (2008). England's Terrestrial Ecosystem Services and the Rationale for an Ecosystem Approach. Overview report. Defra Project Code NR0107.

Hood, C., (1995). The "New Public Management" in the 1980s: Variations on a theme. Accounting, Organizations and Society. 20(2/3), 93-109.

Jansson, M. \& Lindgren, T., (2012). A review of the concept 'management' in relation to urban landscapes and green spaces: Toward a holistic understanding. Urban Forestry \& Urban Greening. 2, 139-145.

Jansson, M. \& Mårtensson, F., (2012). Green school grounds: A collaborative development and research project in Malmö, Sweden. Children, Youth and Environments. 1, 260-269. 
Jansson, M., Vogel, N., Fors, H. \& Randrup, T.B., (2019). The governance of landscape management: New approaches to urban space development. Landscape Research. 44(8), 952-965.

Konijnendijk, C.C., (1999). Urban Forestry in Europe: A Comparative Study of Concepts, Policies and Planning for Forest Conservation, Management and Development in and Around Major European Cities (Ph.D. Thesis). University of Joensuu, Joensuu.

MacKenzie, A., Pearson, L.J. \& Pearson, C.J., (2019). A framework for governance of public green spaces in cities. Landscape Research. 44(4), 444-457.

Maes, J. \& Jacobs, S., (2015). Nature-based solutions for Europe's sustainable development. Conservation Letters. 10(1), 121-124.

Malone, K. \& Tranter, P., (2003). Children's environmental learning and the use, design and management of school-grounds. Children, Youth and Environments. 13, 87-137.

MEA, (2005). Millennium Ecosystem Assessment Report. Ecosystems and Human Well-being: Synthesis. Millennium Ecosystem Assessment. Washington, DC: Island Press.

Molin, J.F., (2014). Parks, People and Places Place-Based Governance in Urban Green Space Maintenance (Ph.D. Thesis). University of Copenhagen, Copenhagen.

Molin, J.F. \& Konijnendijk van den Bosch, C.C., (2014). Between big ideas and daily realities - The roles and perspectives of Danish municipal green space managers on public involvement in green space maintenance. Urban Forestry \& Urban Greening. 13, 553-561.

Morgan, G., (1991). A Strategic Approach to the Planning and Management of Parks and Open Spaces. Berkshire: The Institute of Leisure \& Amenity Management.

Neal, P., (2016). State of UK Public Parks. Research Report to the Heritage Lottery Fund. London: Heritage Lottery Fund.

Newman, P., Beatley, T. \& Boyer, H., (2009). Resilient Cities. Washington, DC: Island Press.

Pickett, S.T.A., Cadenasso, M.L., Grove, J.M., Nilon, C.H., Pouyat, R.V., Zipperer, W.C. \& Costanza, R., (2001). Urban ecological systems: Linking terrestrial ecological, physical, and socioeconomic components of metropolitan areas. Annual Review of Ecology and Systematics. 32(1), 127-157.

Randrup, T.B. \& Persson, B., (2009). Management of public green space in the Nordic countries Development of a new strategic green space management regime. Urban Forestry \& Urban Greening. 8(1), 31-40.

Rodiek, J.E., (2006). Landscape planning: Its contribution to the evolution of the profession of landscape architecture. Landscape and Urban Planning. 76(1), 291-297.

Schmitt-Harsh, M., Mincey, S.K., Patterson, M., Fischer, B.C. \& Evans, T.P., (2013). Private residential urban forest structure and carbon storage in a moderate-sized urban area in the Midwest, United States. Urban Forestry \& Urban Greening. 12(4), 454-463.

Sehested, K., (2004). Democratic consequences of urban governance - What has become of representative democracy? In: P. Bogason, S. Kensen \& H.T. Miller (eds.) Tampering with Tradition: The Unrealized Authority of Democratic Agency. Lanham, MD: Lexington Books. 63-86.

Shams, I. \& Baker, A., (2019). Barriers and opportunities of combining social and ecological functions of urban greenspaces - Users' and landscape professionals' perspectives. Urban Forestry \& Urban Greening. 39, 67-78.

Smith, H., Pereira, M., Hull, A. \& Konijnendijk van den Bosch, C., (2014). The governance of open space decision-making around place-keeping. In: N. Dempsey, H. Smith \& M. Burton (eds.) Place-Keeping: Open Space Management in Practice. London: Routledge. 52-75.

Steiner, F.R., (1991). The Living Landscape: An Ecological Approach to Landscape Planning. New York: McGraw-Hill.

UN, (1998). Aarhus Convention. Access to Information, Public Participation in Decision-Making and Access to Justice in Environmental Matters. Aarhus: United Nations.

van den Brink, A., Bruns, D., Tobi, H. \& Bell, S., (2016). Research in Landscape Architecture: Methods and Methodology. New York: Routledge.

Vogel, N., (2017). Synergies through entanglement: Commoning entering the urban governance realm. The Public Sector. 43(1), 7-18.

All figures are used with permission. 